\title{
Synthesis and Electrochemical Characterization of AgNP Ink Suitable for Inkjet Printing
}

\author{
S. Milardović, ${ }^{1, *}$, I. Ivanišević ${ }^{1}$, A. Rogina ${ }^{2}$ and P. Kassal ${ }^{1}$ \\ ${ }^{1}$ Dept. of General and Inorganic Chemistry, Faculty of Chemical Engineering and Technology, \\ University of Zagreb, Marulićev trg 19, HR-10000 Zagreb, Croatia \\ ${ }^{2}$ Dept. of Inorganic Chemical Technology and Nonmetals, Faculty of Chemical Engineering and \\ Technology, University of Zagreb, Marulićev trg 20, HR-10000 Zagreb, Croatia \\ E-mail: stjepan.milardovic@ fkit.hr
}

doi: $10.20964 / 2018.11 .87$

Received: 20 July 2018 / Accepted: 6 September 2018 / Published: 1 October 2018

To meet the growing demand for inkjet printable nanoparticle-based conductive inks, novel synthetic approaches are needed. In this study, spherical silver nanoparticles (AgNPs) with a mean diameter of approximately $2.5 \mathrm{~nm}$ were synthesized by the reduction of silver nitrate using an aqueous hydrazine solution in the presence of poly(acrylic acid) as a capping agent. The main goal of this work was the implementation of cyclic voltammetry as an electrochemical method for studying both the absorption of poly(acrylic acid) on the grain surface and nanoparticle interactions. The same technique was used to determine equimolar additions of hydrazine to obtain a high yield of reduced silver. All solutions used in the experiments were prepared at a high molar concentration. Silver nanoparticle-based ink was prepared by dispersing dried nanoparticles into a mixture of water and ethylene glycol and was stable for over seven months. For a comprehensive study of the prepared nanoink, UV-visible and electronic microscopy measurements were carried out. An inkjet technology was applied to deposit conductive ink to form linear silver tracks on a flexible substrate. These tracks exhibited a resistivity of $8.0 \times 10^{-8} \Omega \mathrm{m}$.

Keywords: Inkjet printing, cyclic voltammetry, conductive ink, poly(acrylic acid), silver nanoparticles

\section{$\underline{\text { FULL TEXT }}$}

(C) 2018 The Authors. Published by ESG (www.electrochemsci.org). This article is an open access article distributed under the terms and conditions of the Creative Commons Attribution license (http://creativecommons.org/licenses/by/4.0/). 